\title{
Is Oral Mucositis Occurring During Chemotherapy for Esophageal Cancer Patients Correctly Judged? EPOC Observational Cohort Study
}

\author{
YOSHIHIRO TANAKA ${ }^{1}$, TAKAO UENO ${ }^{2}$, NAOYA YOSHIDA ${ }^{3}$, YASUNORI AKUTSU ${ }^{4}$, HIROYA TAKEUCHI $^{5}$, \\ HIDEO BABA $^{3}$, HISAHIRO MATSUBARA ${ }^{4}$, YUKO KITAGAWA ${ }^{6}$ and KAZUHIRO YOSHIDA ${ }^{1}$ \\ ${ }^{1}$ Department of Surgical Oncology, Graduate School of Medicine, Gifu University, Gifu, Japan \\ ${ }^{2}$ Dental Division of National Cancer Center, Tokyo, Japan; \\ ${ }^{3}$ Department of Gastroenterological Surgery, Graduate School of Medical Sciences, \\ Kumamoto University, Kumamoto, Japan; \\ ${ }^{4}$ Department of Frontier Surgery, Graduate School of Medicine, Chiba University, Chiba, Japan; \\ ${ }^{5}$ Department of Surgery, Hamamatsu University School of Medicine, Hamamatsu, Japan; \\ ${ }^{6}$ Department of Surgery, Graduate School of Medicine, Keio University, Tokyo, Japan
}

\begin{abstract}
Background/Aim: Oral mucositis (OM) is one of the frequent adverse events experienced by patients receiving chemotherapy. Most diagnoses of $O M$ are based on complaints from patients. The aim of this study was to develop a tool to diagnose OM accurately. Materials and Methods: A central review system (CRS) was created to allow judgment when the patient background is completely unknown. The primary endpoint was the rate of grade 2 or higher OM, and the secondary endpoint was the difference in grade between each institution's clinician judgement and that of the CRS. Results: In total, 53 patients were registered from four institutions. CRS successfully detected grade 2 or higher OM in 16 (30.2\%) of the 53 patients. The detection rate of all grades of OM was 41.5\% (22 of 53 patients) by each institution's clinician judgement and $84.9 \%$ (45 of 53 patients) by CRS judgement ( $p<0.0001)$. Conclusion: OM during chemotherapy may be underestimated.
\end{abstract}

Esophageal cancer is a malignant disease carrying a poor prognosis in spite of $\mathrm{R} 0$ resection (1). In a previous report, the 5-year survival rates of patients with stage I, II, III, and IV esophageal cancer were $90 \%, 45 \%, 20 \%$, and $10 \%$,

Correspondence to: Yoshihiro Tanaka, MD, Ph.D., Department of Surgical Oncology, Graduate School of Medicine, Gifu University, 1-1 Yanagido, Gifu City, Gifu 501-1194, Japan. Tel: +81 0582306000, Fax: +810582301074, e-mail: yoshihirotana11@ hotmail.com Clinical Trial: UMIN000014573

Key Words: Chemotherapy, oral mucositis, esophageal carcinoma, underestimation, central review system. respectively (2). Recent advances in surgical techniques have reduced complications for advanced esophageal cancer, but the 5-year survival rate is only $20-36 \%$ (3). Even patients with submucosal infiltration have a high potential for lymph node metastases, and the rate of lymph node metastasis is reported to range from $16-62 \%$ (4). The survival of esophageal cancer patients is strongly associated with the extent of lymph node metastasis (5-7).

In patients with operable and node-positive advanced esophageal cancer, there is evidence supporting the use of neoadjuvant chemotherapy or chemoradiation $(8,9)$. Also, metastatic esophageal cancer has been treated with chemotherapy (10), which can significantly improve the survival rate of patients, but causes adverse effects $(11,12)$. The standard neoadjuvant chemotherapy is 5-fluorouracil (5-FU)/ cisplatin (FP) (13). The combination of docetaxel/ cisplatin/ 5-FU (DCF) has become widespread, because of the expectation of higher effectiveness (14). To overcome adverse events including hematological toxicities, we reported a biweekly-DCF regimen which can reduce hematological toxicity $(15,16)$.

Oral mucositis (OM) results in increased pain, difficulty in swallowing, nutritional compromise, and infection. All anticancer agents used in DCF are reported to cause mucosal damage, with an incidence rate of few to as much as $70 \%$ $(17,18)$. However, several countermeasures to prevent OM have been reported (19-21), but their effects might not be sufficient to combat multi-drug anticancer therapies.

One report indicated that administration of oral glutamine (Gln) reduced OM after cancer chemotherapy (22). We previously conducted a randomized phase II trial to verify the effects of Gln plus elemental diet (ED, (Elental ${ }^{\circledR}$; EA 
Pharma Co., Ltd.). Only the Gln plus ED group showed a preventive effect. The ED contains amino acids such as histidine, which has an anti-inflammatory effect (23). The higher level of plasma diamine oxidase activity was achieved in Gln plus ED group (24).

In our next study, the 'EPOC feasibility study' (Feasibility study of the effect of Elemental diet with docetaxel, cisplatin and fluorouracil (DCF) in Preoperative Oesophagus Cancer patients: A multi-center prospective feasibility study), which has already been reported, we investigated compliance to ED that could feasibly be administered in combination with a DCF regimen. We found that $70 \%$ of patients completed the orally administered regimen of ED (160 g/day) (25).

Importantly, the exact objective incidence of OM was not clarified because its incidence was based on complaints of patients or assessment by general physicians or medical staff who are not specialists in the oral environment, and thus the incidence of $\mathrm{OM}$ might have been underestimated. A thorough examination of the intraoral condition by use of instruments designed for the oral cavity can only be conducted by oral and maxillofacial surgeons, dentists, and their teams.

Considering the above situation, a central review system (CRS) was developed for judging the oral environment. To determine the feasibility and objectivity of this system, a multi-center, prospective, observational cohort study was conducted on the incidence of OM in esophageal cancer patients treated with practical chemotherapy using the CRS.

\section{Materials and Methods}

Establishment of a CRS for practical chemotherapy. Initially, we developed the CRS in line with a multi-center, prospective, observational cohort study investigating practical chemotherapy for esophageal cancer. Patients with esophageal cancer undergoing chemotherapy with FP or triplet regimen were enrolled from 4 institutions: Gifu University Hospital, Keio University Hospital, Kumamoto University Hospital, and Chiba University Hospital. Dentists and oral and maxillofacial surgeons at each institution used instruments specific for the oral cavity and a specialized intraoral imaging camera to take six photographs of the posterior surface of the upper and lower lip, right and left buccal mucosa, and right and left lingual surfaces of each patient (Figure 1) and stored them as 4-megabyte electronic files in the CRS data server before the start of chemotherapy and at every cycle of chemotherapy without grading OM.

In addition, each institution's clinicians assessed and recorded the incidence and grade of $\mathrm{OM}$ at bedside without specific instruments for the oral cavity. Treatment of OM, if needed, was at the discretion of the clinicians of each institution as daily routine medical management of OM.

Separately, a dental specialist who was well experienced in dental oncology (TU), not affiliated with any of the registered institutions, and unaware of the patients' backgrounds assessed the incidence and grading of OM using the CRS after the end of all registered patient's chemotherapy.
OM was graded by using the Common Terminology Criteria for Adverse Events (CTCAE) version 3.0 (2003) as follows: Grade 1, erythema of the mucosa; Grade 2, patchy ulcerations or pseudomembranes; Grade 3, confluent ulcerations or pseudomembranes, bleeding with minor trauma; Grade 4, tissue necrosis, significant spontaneous bleeding, life-threatening consequences; and Grade 5, death. The judgment grade was recorded for all patients, and any difference between the CRS judgement and that made at the bedside by each institution's clinicians was investigated.

Endpoints. The primary endpoint of this study was validity of the CRS judgment. In other words, verification of the rate of grade 2 or higher OM occurred in daily clinical practice as judged by the CRS. The secondary endpoints were the difference between the judgment by each institution's clinicians at the bedside and the CRS judgement and all adverse events other than OM that resulted from daily esophageal cancer chemotherapy.

Eligibility criteria. Patients who were $>18$ years of age at the time of registration and who had histologically or cytologically confirmed esophageal squamous cell carcinoma or adenocarcinoma were included. The other inclusion criteria were as follows: an Eastern Cooperative Oncology Group performance status of 0-2; a life expectancy of $>12$ weeks; adequate liver, bone marrow, renal, and cardiovascular functions (serum bilirubin $\leq 1.5 \mathrm{mg} / \mathrm{dl}$; neutrophil count $\geq 1500 / \mathrm{mm}^{3}$; serum aspartate aminotransferase and alanine aminotransferase levels $\leq$ twice the upper limit of normal range; platelet count $\geq 10 \times 10^{4} / \mathrm{mm}^{3}$; hemoglobin $\geq 8.0 \mathrm{~g} / \mathrm{dl}$; and creatinine $\leq 1.2 \mathrm{mg} / \mathrm{dl}$ ).

The major exclusion criteria were serious concomitant illness, symptomatic infectious disease, severe allergy, peripheral neuropathy, or uncontrolled diabetes mellitus.

Ethical considerations. This trial was conducted in accordance with the World Medical Association Declaration of Helsinki and was registered with the University Hospital Medical Information Network Clinical Trials Registry (Registration number: UMIN000014573). The study protocol was approved by the independent ethics committees of each of the four participating institutions, and written informed consent was obtained from all of the patients.

Statistical analysis. The differences in the judgement of OM between each institution's clinicians and the CRS was analyzed by Wilcoxon rank sum test and Fisher's exact test. $p$-Values of $<0.05$ were considered to indicate statistical significance. All statistical analyses were performed using the SAS software program (ver. 9.4; SAS Institute Inc., Cary, NC, USA).

\section{Results}

Establishment of a CRS for practical chemotherapy. Chemotherapy for esophageal cancer was performed in 53 patients between January 2013 and March 2015. Patient characteristics are shown in Table I. All 53 patients were enrolled, and all were targeted as subjects for the analysis of the primary endpoint. The median age was 67 years (range $=50$ 81 years). Performance status was 0 in 16 patients and 1 in 27 patients. Tissue types included squamous cell carcinoma in 52 (98.1\%) patients and adenocarcinoma in 1 (1.9\%) patient. 

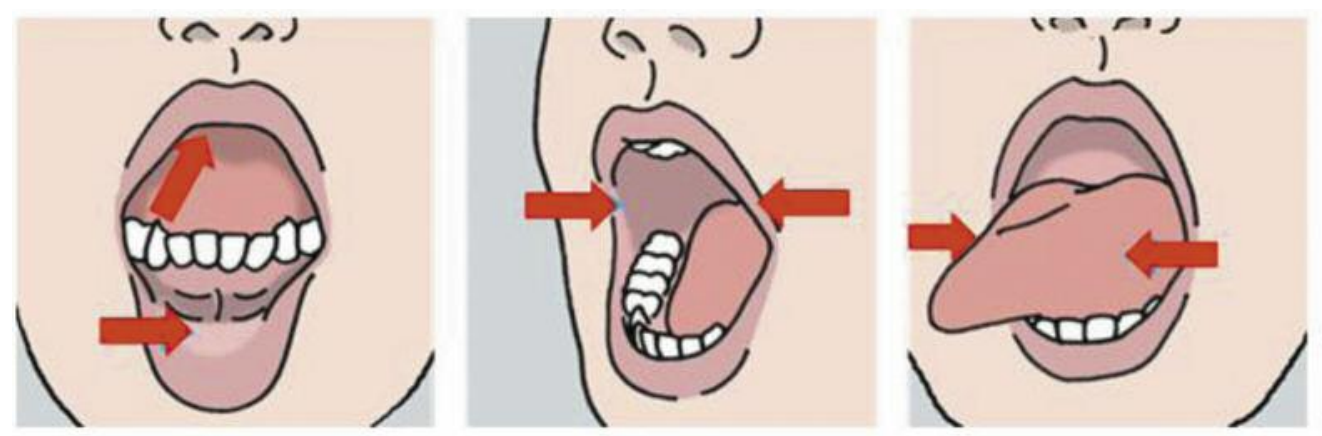

Figure 1. Schema of the intraoral photographs for the central review system. Oral and maxillofacial surgeons used a specialized intraoral imaging camera to take six photographs of the posterior surface of the upper and lower lip, right and left buccal mucosa, and right and left lingual surface.

Table I. Patient characteristics.

Number of patients $(n=53)$

Age, years
Median (range)
Gender
Males/Females
ECOG performance status
0/1/2/Missing data
Histological type
Squamous cell carcinoma/Adenocarcinoma
Differentiation
Well/Moderate/Poor/Unknown
Site of primary tumor
Ce/Ut/Mt/Lt/Ae/Missing data
Clinical T stage
cT1b/T2/T3/T4
Clinical N stage
cN0/N1/N2/N3/N4
Clinical stage
II/III/IV
Pretreatment surgery
Yes/No/Missing data
Pretreatment chemotherapy
Yes/No/Missing data
Pretreatment radiotherapy
Yes/No/Missing data
$67(50-81)$

$47 / 6$

$88.7 / 11.3$

$16 / 27 / 9 / 1$

$52 / 1$

$10 / 20 / 6 / 17$

$8 / 10 / 22 / 12 / 0 / 1$

$4 / 4 / 22 / 23$

$3 / 8 / 15 / 26 / 1$

$4 / 26 / 23$

$2 / 50 / 1$

$4 / 48 / 1$

$1 / 51 / 1$
$18.9 / 37.7 / 11.3 / 32.1$

$30.2 / 50.9 / 17.0 / 1.9$

$98.1 / 1.9$

$15.1 / 18.9 / 41.5 / 22.6 / 0.0 / 1.9$

$7.5 / 7.5 / 41.5 / 43.4$

$5.7 / 15.1 / 28.3 / 49.1 / 1.9$

$7.5 / 49.1 / 43.4$

3.8/94.3/1.9

$7.5 / 90.6 / 1.9$

$1.9 / 96.2 / 1.9$

ECOG: Eastern Cooperative Oncology Group; Ce: cervical esophagus; Ut: upper thoracic esophagus; Mt: middle thoracic esophagus; Lt: lower thoracic esophagus; Ae: abdominal esophagus.

Chemotherapy regimens performed were a DCF regimen in 36 $(67.9 \%)$, DGS (docetaxel, nedaplatin, and S-1) regimen (26) in $7(13.2 \%)$, and the FP regimen in 10 patients $(18.9 \%)$.

Central review of oral photographs using the CRS was achieved for all patients, and the CRS judge could assess the incidence and grading with objectivity. Accordingly, OM of all grades occurred in 45 patients $(84.9 \%, 95 \%$ confidence interval $(\mathrm{CI})=72.4-93.3 \%)$. OM of grade 2 or higher was found in 16 patients $(30.2 \%, 95 \% \mathrm{CI}=18.3-44.3 \%)$.
The all grades of OM judged by each institution's clinicians at the bedside was $41.5 \%$ (22 of 53 patients; 95\% CI $=28.5-55.9 \%$ ). Judgment of all grades of OM by each institution's clinician was significantly lower than that made with the CRS $(p<0.0001)$ (Table II).

All adverse events. Among hematological adverse events, grade 3 or higher leucopenia occurred in 18 (34.0\%) and grade 3 or higher neutropenia occurred in $19(35.8 \%)$ 
Table II. Difference of judgement between each institution's clinicians and CRS.

\begin{tabular}{lccc}
\hline & Institutional Judge $(\mathrm{n}=53)$ & CRS Judge $(\mathrm{n}=53)$ & $p$-Value \\
\hline Grade 0 & $31(58.5 \%)$ & $8(15.1 \%)$ & $0.0001(\mathrm{~W}) \dagger$ \\
Grade 1 & $12(22.6 \%)$ & $29(54.7 \%)$ & \\
Grade 2 & $9(17.0 \%)$ & $4(22.6 \%)$ & \\
Grade 3 & $1(1.9 \%)$ & $0(0.0 \%)$ & \\
Grade 4 & $0(0.0 \%)$ & $16(30.2 \%)(95 \% \mathrm{CI}=18.3-44.3 \%)$ & $0.2588(\mathrm{~F})$ \\
Grade 2 or higher & $10(18.9 \%)(95 \% \mathrm{CI}=28.2-55.9 \%)$ & $4(7.5 \%)(95 \% \mathrm{CI}=2.1-18.2 \%)$ & $0.3629(\mathrm{~F})$ \\
Grade 3 or higher & $1(1.9 \%)(95 \% \mathrm{CI}=0.0-10.1 \%)$ & $45(84.9 \%)(95 \% \mathrm{CI}=72.4-93.3 \%)$ & $<0.0001(\mathrm{~F}) \dagger$ \\
All grade & $22(41.5 \%)(95 \% \mathrm{CI}=28.5-55.9 \%)$ &
\end{tabular}

(W): Wilcoxon rank sum test; (F): Fisher's exact test; CI: confidence interval; CRS: central review system; ${ }^{\dagger} p<0.05$.

Table III. Adverse events ( $n=53)$.

\begin{tabular}{|c|c|c|c|c|c|c|c|}
\hline & \multicolumn{4}{|c|}{ Grade } & \multirow{2}{*}{$\begin{array}{l}\text { All grades } \\
\text { n }(\%)\end{array}$} & \multirow{2}{*}{$\begin{array}{c}\geq \text { Grade } 2 \\
\text { n (\%) }\end{array}$} & \multirow{2}{*}{$\begin{array}{c}\geq \text { Grade } 3 \\
n(\%)\end{array}$} \\
\hline & 1 & 2 & 3 & 4 & & & \\
\hline Hearing disturbance & 1 & 0 & 0 & 0 & $1(1.9)$ & $0(0.0)$ & $0(0.0)$ \\
\hline Fatigue & 6 & 2 & 0 & 0 & $8(15.1)$ & $2(3.8)$ & $0(0.0)$ \\
\hline Fever & 4 & 1 & 0 & 0 & $5(9.4)$ & $1(1.9)$ & $0(0.0)$ \\
\hline Alopecia & 30 & 9 & - & - & $39(73.6)$ & $9(17.0)$ & - \\
\hline Pigmentation & 0 & 0 & 0 & 0 & $0(0.0)$ & $0(0.0)$ & $0(0.0)$ \\
\hline Skin rash & 0 & 0 & 0 & 0 & $0(0.0)$ & $0(0.0)$ & $0(0.0)$ \\
\hline Cutaneous symptoms of the hands and feet & 1 & 0 & 0 & 0 & $1(1.9)$ & $0(0.0)$ & $0(0.0)$ \\
\hline Anorexia & 15 & 7 & 3 & 0 & $25(47.2)$ & $10(18.9)$ & $3(5.7)$ \\
\hline Constipation & 2 & 0 & 0 & 0 & $2(3.8)$ & $0(0.0)$ & $0(0.0)$ \\
\hline Diarrhea & 6 & 2 & 0 & 0 & $8(15.1)$ & $2(3.8)$ & $0(0.0)$ \\
\hline Nausea & 5 & 1 & 0 & 0 & $6(11.3)$ & $1(1.9)$ & $0(0.0)$ \\
\hline Infection (accompanied by neutropenia) & 1 & 3 & 0 & 0 & $4(7.5)$ & $3(5.7)$ & $0(0.0)$ \\
\hline Edema & 4 & 0 & 0 & 0 & $4(7.5)$ & $0(0.0)$ & $0(0.0)$ \\
\hline Neuropathy (motor) & 2 & 0 & 0 & 0 & $2(3.8)$ & $0(0.0)$ & $0(0.0)$ \\
\hline Neuropathy (sensory) & 3 & 1 & 0 & 0 & $4(7.5)$ & $1(1.9)$ & $0(0.0)$ \\
\hline Watery eyes & 1 & 0 & 0 & 0 & $1(1.9)$ & $0(0.0)$ & $0(0.0)$ \\
\hline Leucopenia & - & 14 & 15 & 3 & $32(60.4)$ & $32(60.4)$ & $18(34.0)$ \\
\hline Neutropenia & - & 9 & 11 & 8 & $28(52.8)$ & $28(52.8)$ & $19(35.8)$ \\
\hline Anemia & - & 27 & 2 & 0 & $29(54.7)$ & $29(54.7)$ & $2(3.8)$ \\
\hline Thrombocytopenia & - & 5 & 1 & 0 & $6(11.3)$ & $6(11.3)$ & $1(1.9)$ \\
\hline
\end{tabular}

patients. Among the non-hematological adverse events, anorexia of grade 2 or higher occuured in 10 patients $(18.9 \%)$, and diarrhea of grade 2 or higher occurred in 2 patients $(3.8 \%)$. Anorexia of grade 3 was recognized in 3 patients $(5.7 \%)$ (Table III).

\section{Discussion}

This is the first study, to our knowledge, of the development of a CRS for judgment of OM by a dental specialist well experienced in dental oncology who could judge OM in an unbiased manner, without knowledge of the patient's background. Moreover, dentists at each participating institution used special equipment for intraoral photography which were stored in a central server at high resolution.

The incidence of OM (grade $\geq 1$ ) during chemotherapy has been reported to be higher in breast cancer $(76.5 \%)$, followed by head and neck cancer $(67.7 \%)$, colorectal cancer $(63 \%)$, and esophageal cancer $(57.8 \%)$. The incidence of OM was higher in DCF (85.7\%), followed by 5-FU/ leucovorin/ irinotecan $(80 \%)$, and 5-FU/cyclophosphamide/adriamycin $(78.8 \%)$. The incidence of $\mathrm{OM}$ of grade $\geq 2$ among patients receiving DCF was approximately $40 \%$ (27).

In this prospective cohort study, intraoral assessment via an objective central review system by an oral and maxillofacial surgery specialist as CRS judge could be 
Table IV. Therapeutic drugs and the presence or absence of ED.

\begin{tabular}{|c|c|c|c|c|c|}
\hline \multirow[b]{2}{*}{ Regimen } & \multirow[b]{2}{*}{ Dose $\left(\mathrm{mg} / \mathrm{m}^{2}\right)$} & \multirow{2}{*}{$\frac{\mathrm{n}=53}{\mathrm{n}(\%)}$} & \multirow{2}{*}{$\frac{\text { ED group }(\mathrm{n}=8)}{\mathrm{n}(\%)}$} & \multirow{2}{*}{$\begin{array}{c}\text { Non-ED group }(\mathrm{n}=45) \\
\mathrm{n}(\%)\end{array}$} & \multirow[t]{2}{*}{$p$-Value } \\
\hline & & & & & \\
\hline \multicolumn{6}{|c|}{ Docetaxel.Cisplatin.5-Fu (DCF) } \\
\hline DCF 3 courses & D:70, C:70, F:750 & $1(1.9)$ & $0(0.0)$ & $1(2.2)$ & 1.0000 \\
\hline Biweekly-DCF 2 courses & $\mathrm{D}: 35, \mathrm{C}: 40, \mathrm{~F}: 400$ & $22(41.5)$ & $4(50.0)$ & $18(40.0)$ & 0.7048 \\
\hline Biweekly-DCF 1.5 courses & $\mathrm{D}: 35, \mathrm{C}: 40, \mathrm{~F}: 400$ & $2(3.8)$ & $0(0.0)$ & $2(4.4)$ & 1.0000 \\
\hline Biweekly-DCF 1 course & $\mathrm{D}: 35, \mathrm{C}: 40, \mathrm{~F}: 400$ & $4(7.5)$ & $1(12.5)$ & $3(6.7)$ & 0.4912 \\
\hline Modified-DCF 2 courses & D:60, C:6, F:350 & $5(9.4)$ & $0(0.0)$ & $5(11.1)$ & 1.0000 \\
\hline Modified-DCF 1 course & D:60, C:6, F:350 & $2(3.8)$ & $0(0.0)$ & $2(4.4)$ & 1.0000 \\
\hline \multicolumn{6}{|l|}{ Docetaxel. CDGP. S1 (DGS) } \\
\hline DGS 2 courses & $\mathrm{D}: 35, \mathrm{G}: 40, \mathrm{~S} 1: 80$ or 100 & $7(13.2)$ & $2(25.0)$ & $5(11.1)$ & 0.2829 \\
\hline \multicolumn{6}{|l|}{ 5-Fu. CDDP (FP) } \\
\hline FP 2 courses & C:60 80, F:700 1000 & $9(17.0)$ & $0(0.0)$ & $9(20.0)$ & 0.3424 \\
\hline FP 1 course & $\mathrm{C}: 80, \mathrm{~F}: 800$ & $1(1.9)$ & $1(12.5)$ & $0(0.0)$ & 0.1509 \\
\hline
\end{tabular}

Fisher's exact test. ED: Elemental diet; D: docetaxel; C: cisplatin; F: 5-fluorouracil; CDGP: nedaplatin.

Table V. Incidence rates per grade of oral mucositis and incidence rates of oral mucositis with and without ED in the observational study using CRS.

\begin{tabular}{lcccc}
\hline & $\mathrm{n}=53$ & With ED $(\mathrm{n}=8)$ & Without ED $(\mathrm{n}=45)$ & $p$-Value \\
\hline Grade 0 & $8(15.1 \%)$ & $3(37.5 \%)$ & $5(11.1 \%)$ & $0.0682(\mathrm{~W})$ \\
Grade 1 & $29(54.7 \%)$ & $4(50.0 \%)$ & $25(55.6 \%)$ & $11(24.4 \%)$ \\
Grade 2 & $12(22.6 \%)$ & $1(12.5 \%)$ & $4(8.9 \%)$ & $0.0 \%)$ \\
Grade 3 & $4(7.5 \%)$ & $0(0.0 \%)$ & $0(0.0 \%)$ & $0.4098(\mathrm{~F})$ \\
Grade 4 & $0(0.0 \%)$ & $1(12.5 \%)(95 \% \mathrm{CI}=0.3-52.7 \%)$ & $15(33.3 \%)(95 \% \mathrm{CI}=20.0-49.0 \%)$ & $1.0000(\mathrm{~F})$ \\
Grade 2 or higher & & $0(0.0 \%)(95 \% \mathrm{CI}=0.0-32.4 \%)$ & $4(8.9 \%)(95 \% \mathrm{CI}=2.5-21.2 \%)$ & $0.0899(\mathrm{~F})$ \\
Grade 3 or higher & & $5(62.5 \%)(95 \% \mathrm{CI}=24.5-91.5 \%)$ & $40(88.9 \%)(95 \% \mathrm{CI}=75.9-96.3 \%)$ & \\
All grade & & &
\end{tabular}

(W): Wilcoxon rank sum test; (F): Fisher's exact test; CI: confidence interval; ED: elemental diet; CRS: central review system.

performed in all cases and this study suggested that the rate of OM occurrence during esophageal cancer chemotherapy with triplet regimen including 5-FU in actual clinical settings was not at all low: in patients not receiving ED, all grades of OM occurred in 22 of 23 patients $(95.7 \%, 95 \% \mathrm{CI}=78.1$ $99.9 \%$ ) and grade 3 or higher occurred in 3 of 23 patients $(13.0 \%, 95 \% \mathrm{CI}=2.8-33.6 \%)$, whereas in other reports of triplet regimen chemotherapy including 5-FU, all grades of OM occurred in $10 \%-64 \%$ and grade 3 or higher OM occurred in $0.0-6.7 \%$ of patients $(14,16,28)$.

Interestingly, the incidence rate of all grades of $\mathrm{OM}$ reported from each institution's bedside clinicians, who were not experts in the oral environment, was $41.5 \%$ in this cohort study, whereas the rate determined by the CRS judge was $84.9 \%$. We think that methods of intraoral observation using instruments that are specific to oral surgery specialists improve accuracy but they may not be easily used by general clinicians.
It can be seen that the incidence of OM is higher compared to other non-hematologic toxicities during chemotherapy (Table III). Similar to this study, cardiovascular toxicity, dermatological toxicity, nausea, vomiting, diarrhea, constipation, fatigue, infection, thrombosis, and OM have been reported to account for the majority of non-hematologic toxicities of anticancer drugs. Specific preventive methods and recommendations for handling chemotherapy adverse events other than OM have been made (29). OM has a strong impact on patient's quality of life: the burning sensation patients experience may limit basic functions such as speech, eating, or swallowing saliva.

Cytostatic agents such as 5-FU and taxanes and the frequency of administration (prolonged or repeated low-dose administrations) are strongly related to OM (30). According to the MASCC/ISOO Clinical Practice Guidelines, palifermin is the only agent that has been approved as a drug by the US Food and Drug Administration and the European 
Medicines Agency for OM (31). In the MASCC/ISOO and ESMO guidelines, oral care protocols are recommended (31, 32). A review article has reported that oral hygiene protocols, amifostine, benzydamine, calcium phosphate, cryotherapy, and iseganan yield only limited benefits (33). Although oral care and guidance to patients from dentists concerning oral care were performed in 51 of the 53 patients $(96.2 \%)$ in the present study, OM still occurred. Because palifermin is not covered by insurance in Japan, no effective prophylaxis for chemotherapy-induced OM currently exists.

Recent studies have shown that amino acids have a mucosal protective effect and anti-inflammatory effects (34, 35). Even in this actual clinical setting of esophageal cancer chemotherapy, OM tended to be suppressed by the combined use of ED. In this study, 8 patients $(15.1 \%)$ were treated in combination with administration of ED and 45 patients $(84.9 \%)$ were treated without ED. There were no significant differences in chemotherapy regimens between the groups with or without ED administration (Table IV). Using the CRS, we found that the incidence rate of OM of grade 2 or higher tended to be higher in the group without ED ( 1 of 8 patients $(12.5 \%)$ in the group with $\mathrm{ED}, 95 \% \mathrm{CI}=0.3-52.7 \%$, and 15 of 45 patients $(33.3 \%)$ in the group without $\mathrm{ED}$, 95\% CI=20.0-49.0\%; $p=0.4098$, Fisher's exact test) (Table V).

According to Van der Velden et al., neutropenic patients who receive cytotoxic therapy experience mucosal barrier injury or OM. Mucosal barrier injury creates a port-de-entrée for resident microorganisms to cause bloodstream infections and contributes directly to the occurrence of fever by disrupting highly regulated host-microbe interactions, which, even in the absence of an infection, can result in inflammatory reactions. Hence, the concept of 'febrile neutropenia' alone may no longer suffice, and a new concept of 'febrile mucositis' should be recognized as these two concepts are at least complementary. Importantly, this phenomenon is occurring not only in the oral cavity but also in the entire gut (36). Our previous report (24) also showed that chemotherapy reduced the integrity of the intestinal mucosa and a combination of ED and Gln significantly maintained integrity during chemotherapy, indicating that there might be a connection with the environment of the oral cavity. The low value of plasma diamine oxidase activity in patients with OM in that report may prove this 'febrile mucositis' concept. In other words, the possibility that $\mathrm{OM}$ is a marker of the failure of the mucosal defense function of the intestinal tract has been suggested. For this reason, we think that it is necessary to recognize the importance of correctly evaluating chemotherapy-induced OM. In fact, a discrepancy has been reported between the complaint of the patient and the judgment of the physician (37).

This study has two limitations. First, as esophageal cancer itself is a rare cancer, the number of enrolled patients is small. Second, a single dental specialist was used as a CRS judge.

\section{Conclusion}

We found that the use of a CRS is feasible and that patients undergoing chemotherapy for esophageal cancer developed OM at a consistent frequency. Collaboration with oral surgery specialists is meaningful in research to accurately investigate the incidence of OM, and clinical cooperation is clearly possible. The incidence of chemotherapy-induced OM may be underestimated.

\section{Conflicts of Interest}

Dr. Yoshida reports grants, personal fees, and non-financial support from EA Pharma Co., Ltd., Sanofi, Yakult Honsha Co., Ltd., Chugai Pharma Co., Ltd., Taiho Pharma Co., Ltd., Takeda Pharma Co., Ltd., Eli Lilly Japan K.K., Daiichi Sankyo Co., Ltd., Ono Pharma Co., Ltd., Merck Serono Co., Ltd., and Novartis Pharma K.K., and grants from Kyowa Hakko Kirin Co., Ltd. outside the submitted work. Dr. Kitagawa reports grants and honoraria from Yakult Honsha Co., Ltd., Taiho Pharma Co., Ltd., grants from Kyowa Hakko Kirin Co., Ltd., and honoraria from Sanofi K.K., Pfizer Co., Ltd., Nippon Kayaku Co., Ltd., and Bristol-Myers Squibb outside the submitted work. Dr. Matsubara reports grants from EA Pharma Co., Ltd., Yakult Honsha Co., Ltd., Kyowa Hakko Kirin Co., Ltd., and Taiho Pharma Co., Ltd. outside the submitted work. Dr. Baba reports grants from EA Pharma Co., Ltd. outside the submitted work.

\section{Acknowledgements}

This study was partly supported by grants from the clinical trial program for cancer 2016 in the Japan Society of Clinical Oncology and was partly funded by EA Pharma Co., Ltd., Tokyo, Japan. The Authors would like to thank Rise Japan for providing editorial assistance and Meditrix K.K. for analyzing the data.

\section{Authors' Contributions}

KY and YK conceived the study concept and planned the design as principal investigators. YT interpreted the results and drafted the manuscript. KY revised the manuscript draft by adding intellectual insights and providing critical advice. TU, NY, YA, HT, HB, HM, $\mathrm{YK}$, and $\mathrm{KY}$ obtained the data and provided their critical comments to improve the manuscript, and all Authors gave final approval of the final version of the manuscript.

\section{References}

1 Rustgi AK and EL-Serag HB: Esophageal carcinoma. N Engl J Med 371(26): 2499-509, 2014. PMID: 25539106. DOI: 10.1056/ NEJMra1314530

2 Ando N, Ozawa S, Kitagawa Y, Shinozawa Y and Kitajima M: Improvement in the results of surgical treatment of advanced squamous esophageal carcinoma during 15 consecutive years. Ann Surg 232(2): 225-232, 2000. PMID: 10903602. DOI: 10.1097/00000658-200008000-00013

3 Bagheri R, Maddah G, Saedi HS, Sadeghian MH and Roodbari S: Bone marrow involvement in esophageal cancer patients who underwent surgical resection. Eur J Cardiothorac Surg 40(2): 343346, 2011. PMID: 21345693. DOI: 10.1016/j.ejcts.2010. 12.029 
4 Akutsu Y, Uesato M, Shuto K, Kono T, Hoshino I, Horibe D, Sazuka T, Takeshita N, Maruyama T, Isozaki Y, Akanuma N and Matsubara $\mathrm{H}$ : The overall prevalence of metastasis in $\mathrm{T} 1$ esophageal squamous cell carcinoma: a retrospective analysis of 295 patients. Ann Surg 257(6): 1032-1038, 2013. PMID: 23108117. DOI: 10.1097/SLA.0b013e31827017fc

5 Sugawara K, Yamashita H, Uemura Y, Mitsui T, Yagi K, Nishida M, Aikou S, Mori K, Nomura S and Seto Y: Numeric pathologic lymph node classification shows prognostic superiority to topographic $\mathrm{pN}$ classification in esophageal squamous cell carcinoma. Surgery 162(4): 846-856, 2017. PMID: 28739092. DOI: $10.1016 / j . s u r g .2017 .06 .013$

6 Sjoquist KM, Burmeister BH, Smithers BM, Zalcberg JR, Simes RJ, Barbour A and Gebski V; Australasian Gastro-Intestinal Trials Group: Survival after neoadjuvant chemotherapy or chemoradiotherapy for resectable oesophageal carcinoma: an updated meta-analysis. Lancet Oncol 12(7): 681-692, 2011. PMID: 21684205. DOI: 10.1016/S1470-2045(11)70142-5

7 Natsugoe S, Yoshinaka H, Shimada M, Sakamoto F, Morinaga T, Nakano S, Kusano C, Baba M, Takao S and Aikou T: Number of lymph node metastases determined by presurgical ultrasound and endoscopic ultrasound is related to prognosis in patients with esophageal carcinoma. Ann Surg 234(5): 613-618, 2001 PMID: 11685023

8 Ando N: Progress in multidisciplinary treatment for esophageal cancer in Japan as reflected in JCOG studies. Esophagus 8: 151157, 2011.

9 Almhanna K and Strosberg JR: Multimodality approach for locally advanced esophageal cancer. World J Gastroenterol 18(40): 5679-5687, 2011. PMID: 23155307. DOI: 10.3748/ wjg.v18.i40.5679

10 Kranzfelder M, Buchler P, Lange K and Friess H: Treatment options for squamous cell cancer of the esophagus: a systematic review of the literature. J Am Coll Surg 210(3): 351-359, 2010 PMID: 20193900. DOI: 10.1016/j.jamcollsurg.2009.12.010

11 Yamasaki M, Miyata H, Tanaka K, Shiraishi O, Motoori M, Peng YF, Yasuda T, Yano M, Shiozaki H, Mori M and Doki Y: Multicenter phase I/II study of docetaxel, cisplatin and fluorouracil combination chemotherapy in patients with advanced or recurrent squamous cell carcinoma of the esophagus. Oncology 80(5-6): 307-313, 2011. PMID: 21778771 DOI: $10.1159 / 000329806$

12 Tebbutt NC, Cummins MM, Sourjina T, Strickland A, Van Hazel G, Ganju V, Gibbs D, Stockler M, Gebski V and Zalcberg J; Australasian Gastro-Intestinal Trials Group: Randomized, noncomparative phase II study of weekly docetaxel with cisplatin and 5-fluorouracil or with capecitabine in oesophagogastric cancer: the AGITG ATTAX trial. Br J Cancer 102(3): 475-481, 2010. PMID: 20068567. DOI: 10.1038/sj.bjc.6605522

13 Ando N, Kato H, Igaki H, Shinoda M, Ozawa S, Shimizu H, Nakamura T, Yabusaki H, Aoyama N, Kurita A, Ikeda K, Kanda T, Tsujinaka T, Nakamura $\mathrm{K}$ and Fukuda $\mathrm{H}$ : $\mathrm{A}$ randomized trial comparing postoperative adjuvant chemotherapy with cisplatin and 5-fluorouracil versus preoperative chemotherapy for localized advanced squamous cell carcinoma of the thoracic esophagus (JCOG9907). Ann Surg Oncol 19(1): 68-74, 2012. PMID: 21879261. DOI: 10.1245/s 10434-0112049-9

14 Hara H, Tahara M, Daiko H, Kato K, Igaki H, Kadowaki S, Tanaka Y, Hamamoto Y, Matsushita H, Nagase M and Hosoya
Y: Phase II feasibility study of preoperative chemotherapy with docetaxel, cisplatin, and fluorouracil for esophageal squamous cell carcinoma. Cancer Sci 104: 1455-1460, 2013. PMID: 23991649. DOI: $10.1111 /$ cas.12274

15 Tanaka Y, Yoshida K, Sanada Y, Osada S, Yamaguchi K and Takahashi T: Biweekly docetaxel, cisplatin, and 5-fluorouracil (DCF) chemotherapy for advanced esophageal squamous cell carcinoma: a phase I dose-escalation study. Cancer Chemother Pharmacol 66(6): 1159-1165, 2010. PMID: 20878160. DOI: 10.1007/s00280-010-1447-1

16 Tanaka Y, Yoshida K, Yamada A, Tanahashi T, Okumura N, Matsuhashi N, Yamaguchi K and Miyazaki T: Phase II trial of biweekly docetaxel, cisplatin, and 5-fluorouracil chemotherapy for advanced esophageal squamous cell carcinoma. Cancer Chemother Pharmacol 77(6): 1143-1152, 2016. PMID: 26896963. DOI: 10.1007/s00280-016-2985-y

17 Keeffe DM, Schubert MM, Elting LS, Sonis ST, Epstein JB, Raber-Durlacher JE, Migliorati CA, McGuire DB, Hutchins RD and Peterson DE; Mucositis Study Section of the Multinational Association of Supportive Care in Cancer and the International Society for Oral Oncology: Mucositis Study Section of the Multinational Association of Supportive Care in Cancer and the International Society for Oral Oncology: Update clinical practice guidelines for the prevention and treatment of mucositis. Cancer 109(5): 820-831, 2007. PMID: 17236223.

18 Peterson DE, Jones JB and Petit RG 2nd: Randomized, placebocontrolled trial of Saforis for prevention and treatment of oral mucositis in breast cancer patients receiving anthracycline-based chemotherapy. Cancer 109(2): 322-331, 2007. PMID: 17154160.

19 Nomura M, Kamata M, Kojima H, Hayashi K and Sawada S: Irsogladine maleate reduces the incidence of fluorouracil-based chemotherapy-induced oral mucositis. Ann Oncol 24(4): 10621066, 2013. PMID: 23152361. DOI: 10.1093/annonc/mds584

20 Yokota T, Tachibana H, Konishi T, Yurikusa T, Hamauchi S, Sakai K, Nishikawa M, Suzuki M, Naganawa Y, Hagihara T, Tsumaki H, Kubo T, Sato M, Taguri M, Morita S, Eguchi T, Kubota $\mathrm{K}$ and Zenda S: Multicenter phase II study of an oral care program for patients with head and neck cancer receiving chemoradiotherapy. Support Care Cancer 24(7): 3029-3036, 2016. PMID: 26887378. DOI: 10.1007/s00520-016-3122-5

21 Yokota T, Ogawa T, Takahashi S, Okami K, Fujii T, Tanaka K, Iwae S, Ota I, Ueda T, Monden N, Matsuura K, Kojima H, Ueda S, Sasaki K, Fujimoto Y, Hasegawa Y, Beppu T, Nishimori H, Hirano S, Naka Y, Matsushima Y, Fujii M and Tahara M: Efficacy and safety of rebamipide liquid for chemoradiotherapyinduced oral mucositis in patients with head and neck cancer: a multicenter, randomized, double-blind, placebo-controlled, parallel-group phase II study. BMC Cancer 17(1): 314, 2017. PMID: 28476132. DOI: 10.1186/s12885-017-3295-4

22 Anderson PM, Schroeder G and Skubitz KM: Oral glutamine reduces the duration and severity of stomatitis after cytotoxic cancer chemotherapy. Cancer 83(7): 1433-1439, 1998. PMID: 9762946.

23 Andou A, Hisamatsu T, Okamoto S, Chinen H, Kamada N, Kobayashi T, Hashimoto M, Okutsu T, Shimbo K, Takeda T, Matsumoto H, Sato A, Ohtsu H, Suzuki M and Hibi T: Dietary histidine ameliorates murine colitis by inhibition of proinflammatory cytokine production from macrophages. Gastroenterology 136(2): 564-74.e2, 2009. PMID: 19027739. DOI: $10.1053 /$ j.gastro.2008.09.062 
24 Tanaka Y, Takahashi T, Yamaguchi K, Osada S, Shimokawa T and Yoshida K: Elemental diet plus glutamine for the prevention of mucositis in esophageal cancer patients receiving chemotherapy: a feasibility study. Support Care Cancer 24(2): 933-941, 2016. PMID: 26266659. DOI: 10.1007/s00520-015-2864-9

25 Tanaka Y, Ueno T, Yoshida N, Akutsu Y, Takeuchi H, Baba H, Matsubara H, Kitagawa $\mathrm{Y}$ and Yoshida K: The effect of an elemental diet on oral mucositis of esophageal cancer patients treated with DCF chemotherapy: a multi-center prospective feasibility study (EPOC study). Esophagus 15(4): 239-248, 2018. PMID: 30225745. DOI: 10.1007/s10388-018-0620-1

26 Tanaka Y, Yoshida K, Tanahashi T, Okumura N, Matsuhashi N and Yamaguchi K: Phase II trial of neoadjuvant chemotherapy with docetaxel, nedaplatin, and $\mathrm{S} 1$ for advanced esophageal squamous cell carcinoma. Cancer Sci 107(6): 764-772, 2016. PMID: 27061001. DOI: 10.1111/cas.12943

27 Nishimura N, Nakano K, Ueda K, Kodaira M, Yamada S, Mishima Y, Yokoyama M, Terui Y, Takahashi S and Hatake K: Prospective evaluation of incidence and severity of oral mucositis induced by conventional chemotherapy in solid tumors and malignant lymphomas. Support Care Cancer 20(9): 2053-2059, 2012. PMID: 22116139. DOI: 10.1007/s00520-011-1314-6

28 Babu KG, Chaudhuri T, Lakshmaiah KC, Dasappa L, Jacob LA, Babu M, Rudresha AH, Lokesh KN and Rajeev LK: Efficacy and safety of first-line systemic chemotherapy with epirubicin, cisplatin plus 5-fluorouracil and docetaxel, cisplatin plus 5-fluorouracil regimens in locally advanced inoperable or metastatic gastric or gastroesophageal junction adenocarcinoma: A prospective phase II study from South India. Indian J Cancer 54(1): 47-51, 2017. PMID: 29199662. DOI: 10.4103/ijc.IJC_168_17

29 Baldo P, Fornasier G, Ciolfi L, Sartor I and Francescon S: Pharmacovigilance in oncology. Int J Clin Pharm 40(4): 832841, 2018. PMID: 30069667. DOI: 10.1007/s11096-018-0706-9

30 Chaveli-López B: Oral toxicity produced by chemotherapy: A systematic review. J Clin Exp Dent 6(1): e81-90, 2014. PMID: 24596641. DOI: $10.4317 /$ jced.51337

31 Lalla RV, Bowen J, Barasch A, Elting L, Epstein J, Keefe DM, McGuire DB, Migliorati C, Nicolatou-Galitis O, Peterson DE, Raber-Durlacher JE, Sonis ST and Elad S; Mucositis Guidelines Leadership Group of the Multinational Association of Supportive Care in Cancer and International Society of Oral Oncology (MASCC/ISOO): MASCC/ISOO clinical practice guidelines for the management of mucositis secondary to cancer therapy. Cancer 120(10): 1453-1461, 2014. PMID: 24615748. DOI: $10.1002 /$ cncr. 28592
32 Peterson DE, Boers-Doets CB, Bensadoun RJ and Herrstedt J; ESMO Guidelines Committee. Management of oral and gastrointestinal mucosal injury: ESMO Clinical Practice Guidelines for diagnosis, treatment, and follow-up. Ann Oncol Suppl 5: v139-51, 2015. PMID: 26142468.

33 Chaveli-López B and Bagán-Sebastián J: Treatment of oral mucositis due to chemotherapy. J Clin Exp Dent 8(2): e201-9, 2016. PMID: 27034762. DOI: $10.4317 /$ jced .52917

34 Harada K, Ferdous T, Kobayashi H and Ueyama Y: Elemental diet accelerates the recovery from oral mucositis and dermatitis induced by 5 -fluorouracil through the induction of fibroblast growth factor 2. Integr Cancer Ther 17(2): 423-430, 2018. PMID: 28745083. DOI: 10.1177/1534735417721014

35 Harada K, Ferdous T, Mizukami Y and Mishima K: Elemental diet inhibits pro-inflammatory cytokine production in keratinocytes through the suppression of NF- $x \mathrm{~B}$ activation. Oncol Rep 40(1): 361-368, 2018. PMID: 29767264. DOI: 10.3892/or.2018.6440

36 Van der Velden WJ, Herbers AH, Netea MG and Blijlevens NM. Mucosal barrier injury, fever and infection in neutropenic patients with cancer: introducing the paradigm febrile mucositis. Br J Haematol 167(4): 441-452, 2014. PMID: 25196917. DOI: 10.1111/bjh.13113

37 Okada T, Nakajima Y, Nishikage T, Ryotokuji T, Miyawaki Y, Hoshino A, Tokairin Y, Kawada K, Nagai K and Kawano T: A prospective study of nutritional supplementation for preventing oral mucositis in cancer patients receiving chemotherapy. Asia Pac J Clin Nutr 26(1): 42-48, 2017. PMID: 28049260. DOI: 10.6133/apjcn.112015.03 